\title{
Reflexiones en torno a lo ético- deontológico de la práctica profesional del psicólogo: una lectura psicoanalítica
}

\author{
Eliana Jaime Bacile* \\ Yanina Mariel Ferreyra**
}

RESUMEN

El presente trabajo reflexiona sobre las cuestiones e implicancias ÉticoDeontológicas relativas a la práctica profesional del Psicólogo. Así, distingue ambos términos, apuntando a partir de ello, a identificar los dilemas que se despliegan en la actividad profesional, teniendo en cuenta los aportes del Psicoanálisis. Dicha perspectiva transciende el campo del mero abordaje legal para abrir en cambio la necesidad de pensar en términos de subjetividad.

Palabras clave: Ética profesional - deontología - práctica profesional psicología - subjetividad.

\section{Reflexões em torno do ético-deontológico da prática profissional do psicólogo: Uma leitura psicoanalítica}

\footnotetext{
O presente trabalho reflexiona sobre as qüestões e implicancias ÉticoDeontológicas relativas à prática profissional do Psicólogo. Assim, distingue ambos termos, apontando a partir disso, a identificar os dilemas que se despliegan na atividade profissional, tendo em conta os contribuas do Psicoanálisis. Dita perspectiva, transciende o campo do mero abordaje legal para abrir em mudança a necessidade de pensar em termos de subjetividad.
}

Palavras chave: Ética profissional - deontología - prática profissional psicologia - subjetividade.

* Argentina. Licenciada en Psicología. Profesora Asistente en la Cátedra de Deontología y Legislación Profesional en la Facultad de Psicología. Universidad Nacional de Córdoba. Argentina. Investigadora SECyT. Correo electrónico: eli_bacile@hotmail.com

** Argentina. Licenciada y Profesora en Psicología. Profesora Asistente en la Cátedra de Deontología y Legislación Profesional. Facultad de Psicología. Universidad Nacional de Córdoba. Correo electrónico: yani_ferreyra83@hotmail.com 


\section{Reflections on the ethical conduct of professional practice psychologist: A psychoanalytic reading}

\section{ABSTRACT}

This paper reflects the issues and implications Ethical Conduct for Professional Practice of Psychologists. Thus, distinguishing the two terms, pointing from this, identify the dilemmas that are deployed in the profession, taking into account the contributions of psychoanalysis. This perspective, transcends the field of mere legal approach to open on the other hand the need to think in terms of subjectivity.

Key words: Professional ethics - deontology - professional practice psychology - subjectivity. 


\section{Introducción}

"Ser psicoanalista es estar en una posición responsable, la más responsable de todas, en tanto él es aquel, a quien es confiada la operación de una conversión ética radical, aquella que introduce al sujeto en el orden del deseo". Jacques Lacan, 1965

Para comenzar a abordar esta temática resulta fundamental cernir una pregunta. Cuestionamiento que orientará este trabajo y que pretenderemos responder de manera reflexiva, entendiendo al campo de la práctica profesional de los psicólogos.

Sabemos que la articulación de la Deontología, perteneciente al campo de la psicología, con la Ética Profesional, presenta ciertas dificultades que giran en torno a su distinción y diferenciación. Ahora bien, luego de haber sorteado esta problemática cabe interrogarse sobre la Ética propuesta por los desarrollos y las enseñanzas realizadas desde el Psicoanálisis.

Diremos, en principio, que es inherente a esta praxis el tratamiento de la singularidad, apartándose así, de todo planteo que involucre premisas y leyes pertenecientes al orden de lo general, del "para todos". Es claro, entonces, que los puntos de tensión existentes en la práctica profesional se presentan en el desencuentro que en ocasiones se produce entre lo eminentemente DeontológicoLegal y lo subjetivo en juego.

Seplantean, entonces, permanentes preguntasycuestionamientos en cuanto al quehacer profesional que competen a toda la comunidad de psicólogos, quienes deben no solo identificar los principales dilemas éticos que recaen en su accionar, sino también, comprometerse en intentar alcanzar un cierto esclarecimiento acerca de: ¿Qué posicionamiento ético adoptar en el ejercicio de nuestra práctica profesional?

\section{Lo deontológico y lo ético}

En primera instancia, nos detendremos aquí particularmente en lo que constituye el campo Normativo: la Deontología. Término que procede etimológicamente del griego: deon -lo debido, lo conveniente, deber, obligación-, y logía -tratado, conocimiento, estudio-, lo que significa en términos generales: el estudio, ciencia o tratado de lo debido. 
El creador de este término fue Jeremy Bentham (1748-1832), quien lo utilizó para designar una ciencia de lo "conveniente", refiriéndose a la rama de la Ética cuyo objeto de estudio son los fundamentos del deber y las normas morales. Es también conocida como la "Teoría del deber", siendo una de las ramas principales de la Ética normativa.

La primera alusión del término, el autor lo realizó en su obra denominada "Deontología o Ciencia de la moral", "Deontology or The Science of morality" en el año 1834. Allí Bentham edifica una deontología sobre el Utilitarismo.

El utilitarismo en su forma clásica propone el principio de utilidad, como le llama Bentham, que establece que una acción es moralmente buena cuando produce mayores beneficios que perjuicios y un mejor cálculo de buenas consecuencias respecto de cualquier otra acción alternativa. Esto significa que “...habría que proceder siempre de la forma que permita tener el máximo beneficio individual y colectivo (el mayor beneficio, para el mayor número de personas) o el menor perjuicio posible. La utilidad también puede ser traducida en función de la felicidad o placer y de lo contrario, de evitar el dolor y el sufrimiento" (Zuluaga, 2001). Al respecto Bentham identifica el "bien" con el placer o la felicidad, y el mal con el dolor o la infelicidad (Mainetti, 1991: 36).

La Deontología es entendida como el tratado de los deberes y la descripción de las normas, determinando los límites del quehacer profesional. El origen de las diversas regulaciones deontológicas lo encontramos en el Código de Nüremberg (1947).

Su concepto básico es que obrar "de acuerdo a la Ética" se corresponde con obrar de acuerdo a un código definido previamente. El apartamiento de una norma definida de antemano, en general de forma escrita, constituye una actitud o un procedimiento no-ético.

Así, un Código Deontológico es el documento que acopia un conjunto de criterios, normas y valores que expresan y se adjudican quienes llevan a cabo una actividad profesional. Los Códigos Deontológicos se ocupan de los aspectos más esenciales, cardinales y fundamentales de un ejercicio profesional particular.

La Deontología contempla las obligaciones, deberes y derechos dentro de un campo de acción profesional, es decir, enunciados 
normativos plasmados en los Códigos de Ética. De esta manera, como plantea Hermosilla (2000), “...no es más que la moral profesional, entendida ésta como una serie de principios morales consensuados por un grupo profesional en determinado período epocal" (Hermosilla 2002:30). Hay que precisar aquí que Ética y Moral poseen etimológicamente el mismo significado, por lo cual es frecuente utilizar estos términos de manera inapropiada. Hermosilla (2000) nos aclara sobre esta diferencia diciendo que Ética proviene del griego "ethos" y moral del latín "moris"; ambos significan "costumbre" en sentido amplio; sus connotaciones suelen ser intencionalmente diferenciadas, asignándole a la moral aquellas normas aceptadas por un grupo humano en un tiempo histórico y en una geografía determinada; la ética, en cambio, requiere un ejercicio reflexivo donde la norma es tomada y elegida con asunción de la responsabilidad sobre los efectos del acto" (Hermosilla 2002:12). Sin embargo, es preciso tener en cuenta como nos advierte Peralta (2004), que existe una imposibilidad de establecer con claridad y certeza qué es la Ética.

Las teorías que se denominan deontológicas ( del gr. Deon = deber) establecen que es bueno hacer lo que se debe. Resumidamente, la Ética normativa es la Ética que estudia la clasificación de los actos humanos en correctos e incorrectos renunciando a los prejuicios. La Ética normativa considera a la Ética como un conjunto de normas que se relacionan con acciones, es decir proporcionan maneras de proceder ante las situaciones y respuestas prácticas a la pregunta ¿qué debo hacer...?

Como ya fue señalado, las regulaciones deontológicas encuentran su establecimiento en leyes, códigos normativos vigentes, siendo ejercida y sustentada por instituciones que las amparan, como organismos de control y supervisión de su cumplimiento entre otras funciones. Cuando hacemos referencia a los códigos, nos remitimos a un cuerpo de normas, a un conjunto unitario de normas, ordenado y sistematizado de forma metódica. Las normas son reglas, proposiciones prescriptivas, guiadas por principios -fundamentos-, que conciernen a acciones humanas. Cuando adquieren la característica de criterios de juicio coactivos tienen el estatuto de ley. La ley en tanto norma jurídica, es un precepto establecido que ordena o prohíbe algo en consonancia con la justicia.

Ahora bien, pasaremos a mencionar las características propias de las Leyes, las cuales son: 
- Generales, de modo que comprenden a todo aquel que se encuentre bajo las condiciones que la misma prevé.

- Tiene carácter de obligatoriedad, por una parte establece obligaciones o deberes jurídicos y por la otra, otorga derechos -imperativo-atributivo-. La ley manda, incluso en contra de la voluntad de sus destinatarios. Su incumplimiento da lugar a una sanción, a un castigo establecido por ella misma.

- Se establecen con carácter indefinido, permanente, sólo dejan de tener vigencia por razón de su abrogación, subrogación y derogación por otras leyes que le son posteriores.

- Tienen la característica de ser abstractas e impersonales, ya que no se emiten para regular o resolver casos individuales, ni para personas o grupos determinados, siendo estos aspectos los que determinan su generalidad.

- Nadie puede invocar el desconocimiento o ignorancia de una ley por su no cumplimiento.

De acuerdo a lo señalado, podemos decir que un Código de Ética, como un cúmulo de normas guiadas por principios, y sancionadas públicamente -leyes-, regula y cumple su función normativa y legisladora en el ámbito de una determinada profesión, explicitando e imponiendo aquellos límites a los cuales tienen que remitirse los profesionales -incumbencias- como así también, detalla los puntos en los que se ven obligados aquellos en el ejercicio de su práctica profesional; de esta manera los códigos normativos alertan a los profesionales sobre los límites de su práctica, enfatizan los principios por los que deben regirse, orientan, sirven de guía, resguardan al profesional responsable, promueven la identidad y respeto profesional, jerarquizando su rol social, garantizando ciertos derechos, etcétera.

Por lo tanto, los códigos de ética son cuerpos normativos que tienen el propósito de resguardar tanto a los sujetos que demandan la pericia del profesional, como a los profesionales mismos; aspira a la excelencia y al respeto por los Derechos Humanos, que tienen como referencia a la Constitución Nacional. Es decir, que los Códigos de Ética tienen como correlato la protección de los derechos de las personas, encontrando su sustento en las leyes del Derecho Positivo y su referencia última en los Derechos Humanos.

Si hacemos especial referencia a los derechos protegidos, los Códigos de Ética profesional velan por el derecho a la privacidad, a la confidencialidad, la autodeterminación y la autonomía de las 
personas. Los códigos se fueron construyendo según las visiones y concepciones acerca del mundo y de hombre que hubo en las diferentes épocas, es decir, son construcciones culturales y sociales que han ido variando/cambiando a lo largo de la historia.

Con respecto a los códigos de ética profesional, Domínguez y Salomone (2006) destacan tres puntos relevantes en relación a los mismos:

- Los Códigos de ética establecen una serie de pautas que regulan nuestra práctica, funcionando como una referencia anticipada a situaciones posibles y por venir, es decir, los códigos abarcan todos los casos posibles, en todas las circunstancias posibles y para todos los sujetos. El campo normativo tiende a configurarse y funcionar como un universo. La norma ordena más allá del uno a uno haciendo homogéneos a los "cada uno" en un "todos". Y lo singular de cada caso, de cada sujeto (siempre único, diverso, heterogéneo) no está contemplado en la norma.

- Resumen el conocimiento alcanzado en el campo profesional hasta cierto momento histórico, el cual funciona como fundamento de las normativas, es decir, los códigos de ética se sancionan en un momento histórico, político y social particular y esas regulaciones profesionales que se sancionan constituyen el conocimiento que antecede a una situación dada, porejemploel Código de Ética de la Provincia de Córdoba (Resolución n 5), sancionado en 1987 por el entonces Consejo de Psicólogos de la Provincia de Córdoba (Argentina) (fusionado por la ley 8312 como el Colegio de Psicólogos de la Provincia de Córdoba en 1993), fue uno de los primeros códigos de ética en el país. Así, se estipula en el mismo los deberes y obligaciones del psicólogo en el campo profesional, abarcando o contemplando una serie de circunstancias que hoy podríamos claramente afirmar que lo exceden ampliamente; existen casos, situaciones, dilemas, conflictivas éticas en el ejercicio profesional del psicólogo, nuevas y complejas, que a fines de los '80, cuando se constituye este código, no se habían pensado ni contemplado.

- Las normativas de los códigos encuentran una referencia jerárquicamente superior en las normas jurídicas (nos referimos al Código Penal y al código Civil en la Argentina), ejemplo: en relación al Secreto Profesional en Argentina encontramos su referencia en el Art. 156 del Código Penal 
Argentino: "Será reprimido con multa e inhabilitación especial en su caso, por 6 meses a 3 años el que, teniendo noticia por razón de su estado, oficio, empleo, profesión o arte, de un secreto cuya divulgación pueda causar daño, lo revelare sin justa causa". A su vez, las normas jurídicas nacionales están afectadas por la legislación internacional, por lo cual los lineamientos deontológicos estarán influidos también por valores y principios consensuados internacionalmente.

Así, los códigos deontológicos al ser producidos en el seno de una comunidad que participa de la comunidad mundial, resumen los valores y principios consensuados y sostenidos por la comunidad profesional y social en su conjunto en un tiempo histórico determinado.

De esta manera, los códigos no contienen todas las situaciones posibles del acontecer de la práctica; se constituyen en un cuerpo normativo orientador que, al contener Principios Éticos Superiores, facilita que frente a la insuficiencia o ausencia de la norma, el profesional enfrentado a un dilema Ético, pueda guiarse por el Principio Superior.

Hablar de Principios nos remite directamente a Kant, quien "formuló los principios del ethos, y que propuso una concepción autónoma que se afirma en la razón humana y exenta de cualquier influencia metafísica" (Casas 2000:21). La ética de Kant es una ética autónoma que tiene lugar en el hombre, el cual es un ser racional, y esta racionalidad supone que para el hombre tiene sentido la determinación de la propia conducta, la determinación de la praxis.

Supone al hombre como un ser racional finito que necesita de principios a priori para determinar su conducta, su praxis y su conocimiento, que no es sólo razón -razón pura-, sino también sensibilidad -razón práctica-. Se comprende entonces que la moralidad del hombre tiene la posibilidad de dejarse guiar por la razón y con ella del deber, o seguir sus inclinaciones egoístas, propias de su sensibilidad. En esto radica su posibilidad de elección y de acción, por lo tanto se lo entiende libre. La libertad es una idea regulativa de la moral, es el principio que hace al hombre un ser moral.

Se desprende de lo expresado la idea en Kant de una moralidad que tiene como principio fundamental la razón, que limita a la 
voluntad mediante el imperativo. La moral se realiza en la praxis. Y, como ya anticipamos, la razón práctica analiza los principios a priori de la praxis ética; son estos principios los que Kant llama imperativos.

Los principios prácticos del orden moral, es decir, los imperativos categóricos, son reglas de acción con validez absoluta, universal para todo hombre y en cualquier circunstancia. Mainetti (1998) ponederelieveel imperativocategórico deesta manera: "Laética de Kant (1724-1804) representa una posición deontológica rigurosa, en la cual las consideraciones teleológicas o consecuencialistas resultan irrelevantes. Las obligaciones o deberes morales no son "imperativos hipotéticos", del tipo "si quiero tal cosa debo hacer tal otra" (...) sino "imperativos categóricos", de la forma "debo hacer esto... y punto", fundados en la razón y derivados de un principio que toda persona racional debe aceptar; es el Imperativo Categórico, cuya primera formulación reza así: “Obra de modo que puedas querer la máxima de tu acción como la ley universal" (Mainetti 1998: 39).

De allí que los principios son guías generales, orientadoras, que dejan lugar al juicio particular en casos específicos y que ayudan explícitamente en el desarrollo de las reglas y líneas de acción más detalladas. Las reglas tienen un contenido más específico y un alcance más restringido que los principios y funcionan como normas de conducta más precisas, y establecen cómo se debe actuar en cada circunstancia.

En este sentido es que los códigos pretenden acordar principios éticos básicos y fundamentales. Aquellos comunes a todos los códigos son los que conocemos bajo el nombre de "Principios Éticos Universales del mundo occidental".

Así, los Principios orientan el proceso de constitución de la norma recibiendo de ellos su contenido. De ellos se desprenden las disposiciones deontológicas, normas éticas o deberes que rigen el desempeño profesional de todas las profesiones pero particularmente la del psicólogo, sea en el área de ejercicio o el contexto que sea, como el Consentimiento Informado, el Secreto Profesional y la Honestidad Intelectual.

\section{Ética Psicoanalítica}

A nuestro entender la originalidad de la discursividad que Freud inaugura es circunscribible a una ética. "Freud, al término de 
su pensamiento, vuelve a encontrar el campo de das Ding y nos designa el plano de más allá del principio del placer a nivel de la buena y la mala voluntad, incluso de la preferencia por la mala a nivel de la reacción terapéutica negativa. El campo de das Ding es encontrado nuevamente como una paradoja ética y Freud nos designa en él aquello que en la vida puede preferir la muerte. Y se aproxima así, más que cualquier otro, al problema del mal, más precisamente al proyecto del mal como tal." (Lacan, 2005: 128-129).

El planteo freudiano en relación a la pulsión de muerte pone en tela de juicio la búsqueda del bienestar; el más allá del principio del placer da cuenta de que el soberano bien no existe, y de esta manera Freud otorga a su experiencia y la asienta en la dimensión fundamentalmente ética, puesto que realiza un desplazamiento y se distancia de los planteos moralistas. Dice Lacan en el seminario dedicado a la ética: "la ética del análisis -pues hay una- entraña el borramiento, el oscurecimiento, el retroceso, incluso la ausencia de una dimensión cuyo término basta decir para percatarse de lo que nos separa de toda la articulación ética que nos precede -el hábito, el buen o mal hábito-" (Lacan 2005 b: 20).

La ética psicoanalítica se aparta notoriamente de aquella disciplina que entiende a la felicidad como posible cuando las virtudes se consuman y los excesos se evitan, siendo que serían estos los dos aspectos que posibilitan y permiten realizar elecciones y por consiguiente el bien propio. Lacan dice en su Seminario "Aún", que "la idea del Bien en la ética de Aristóteles (... ) se funda enteramente en la existencia de un ser tal que todos los demás seres menos seres que él no pueden tener otra meta que la de ser lo más ser que puedan" (Lacan 2005: 100).

Freud entendía que los requerimientos de la moral civilizada llevaban al sujeto al malestar, a la enfermedad, puesto que al enfrentarse con las pulsiones de aquel se debatían con ellas y, no pudiendo hallar el camino de la sublimación, sobrevenían los síntomas. Leemos a Freud en la conferencia de la Transferencia: "Podemos imputar redondamente a la sociedad que lo que ella llama su moral cuesta más sacrificios de los que vale, que su procedimiento no se basa en la sinceridad ni testimonia sabiduría" (Freud 1992: 394).

De modo que para Freud la moral era de naturaleza patógena, que en el interior del aparato psíquico se instala en el Superyó, instancia que a medida que el yo cede a sus exigencias cobra 
más fuerza, volviéndose más cruel, más dolorosa y más culposa. Es decir, que los esfuerzos para mitigar las exigencias que tal instancia demanda, habrán de provocar un efecto que siendo opuesto al deseado tiene como corolario mayor malestar; esto es lo que conocemos como sentimiento de culpa. Tanto en Freud como en Lacan, la conciencia de culpa al volverse contra sí misma desgarra al sujeto. La moral, entonces, oculta lo más tanático y destructivo que disfraza, volviendo ocultos los deseos prohibidos del sujeto.

Dirá Freud en "Inhibición Síntoma y Angustia" (1925): "Este disfraz de los impulsos eróticos y las enérgicas formaciones reactivas del yo hacen que la lucha contra la sexualidad continúe ahora en nombre de la ética. El yo se resiste, asombrado, contra los impulsos violentos y crueles, enviados por el ello a la conciencia, sin sospechar que obrando así lucha contra deseos eróticos, que de otro modo hubieran escapado a su intervención" (Freud 1925:43).

Diremos entonces que Freud sienta las bases adoptando un nuevo modo de interpretar al sujeto, inaugura una ética que toma otras líneas de análisis, lo cual instaura la diferencia con los diversos planteos existentes.

\section{Reflexiones ético-deontológicas}

Hasta aquí, hemos podido dar cuenta de que el campo normativo apunta a la búsqueda de la instauración de un universal, realiza especulaciones de visiones generales en base a las cuales formaliza y construye normas. Es su función expedirse, de tal modo, que en sus códigos se contemplen todos los casos posibles. Ética sustentada y regida por el supuesto de la existencia del bien universal: la ética del deber, en aras de construir una ética para todos. Mediante sus enunciados, la norma ordena a condición de abolir la singularidad. No habiendo la posibilidad de construcción de normas para cada uno, el rasgo singular es abordado por lo general. Ilusión sustentada desde el supuesto del individuo como caso particular de un orden universal.

Por otro lado, sabemos que con frecuencia la Deontología es tomada como sinónimo de "Ética Profesional". Asociar la Ética Profesional exclusivamente a la Deontología nos plantea ciertas dificultades, ciertos dilemas, como los que plantean Salomone y Domínguez: un desdoblamiento de la función o rol profesional 
que toma dos caras: por un lado, un profesional con deberes de ciudadano, abogando por los derechos de las personas, atendiendo a las exigencias sociales y legales de la profesión, dirigiendo su práctica en función de un sujeto de derecho; por otro lado, lejos de las regulaciones normativas, se encuentra el profesional que lidia con el sufrimiento del paciente, que debe operar con otra concepción de sujeto, que despliega su práctica en el terreno de la transferencia. Se ubica de este lado la responsabilidad profesional ligada más específicamente a las coordenadas de nuestro objeto de estudio y praxis: "el sufrimiento psíquico del sujeto" (Salomone y Domínguez 2006: 45). Por lo cual, diremos que la Ética Profesional no se confunde con la Deontología.

Pensar la Ética profesional en términos de pautas deontológicas genera la fantasía, si no el error, de creer que es allí donde se configura la dimensión ética de la práctica. Es de esta manera que podemos decir que la Ética Profesional involucra una doble dimensión:

- Lo normativo (los códigos de ética, los deberes y obligaciones profesionales, etcétera), configurado sobre la lógica de lo general, desde una perspectiva particular;

- La dimensión clínica, "que no se refiere solamente al trabajo clínico, sino que señala la perspectiva que toma en cuenta la dimensión del sujeto, un modo de lectura y de abordaje desde lo singular, desde la singularidad en situación" (Salomone y Domínguez 2006: 41).

Será necesario, entonces, no identificar la Ética Profesional exclusivamente a la deontología, es decir, a las regulaciones normativas del ejercicio profesional, sino en cambio: “... entender la ética profesional en su doble dimensión, constituida por las regulaciones de la práctica, pero también por la dimensión clínica que introduce entonces la perspectiva de la singularidad" (Salomone y Dominguez 2006: 41).

Desde esta perspectiva, la propuesta y el desafío radica en la interpretación de aquello establecido por las normas y los códigos deontológicos ya consensuados, a la luz de la dimensión del sujeto, es decir, la posición del mismo profesional frente al campo normativo. Por lo cual, incluir la dimensión del sujeto en el campo de la ética profesional, lleva por una parte a considerar las implicancias clínicas que las prescripciones del campo normativo conllevan y, por otra, insta a la reflexión ética sobre nuestras propias decisiones. Inclusión que responde a la orientación que 
busca el surgimiento, la localización de una dimensión ética, que frente al deseo de cada sujeto, concibe el impedimento justificado de universalización.

\section{Consideraciones finales}

El campo que denominamos bajo la designación de legislativo es de suma importancia para el quehacer profesional del psicólogo, ya sea que desarrolle su actividad a nivel privado o que la realice bajo el ámbito de alguna institución: hospital, institución educativa, jurídica o sanitaria.

En el desempeño de su práctica, el psicólogo debe tener siempre en consideración las legislaciones presentes y vigentes a nivel deontológico. Esto implica conocer acabadamente derechos y deberes propios del rol y que, ambos, son soporte de la ética propia de cada uno.

Siendo que en el ejercicio de la práctica profesional de la Psicología se encuentran involucradas cuestiones relativas a la Deontología y la Ética Profesional, como así también aspectos subjetivos propios, el psicólogo confrontado a estas tensiones inherentes a su campo de acción, deberá posicionarse crítica y reflexivamente, desde su propio bagaje teórico y ético.

A lo largo de este trabajo consideramos fundamental poner a dialogar estas dos grandes dimensiones inherentes al ejercicio de la práctica profesional del psicólogo. Su importancia radica en acceder a una posible reflexión sobre sus puntos de encuentros y desencuentros, no manteniendo una relación de exclusión (o uno o el otro), sino sostener la complejidad que involucra, ya que la confluencia de ambas dimensiones, dan cuenta de diferentes aspectos de la responsabilidad ligada a la práctica de la profesión.

Es por ello, que enlazamos lo ético-deontológico en la práctica profesional en el preciso instante del "entre" de ambas dimensiones: "entre" la posición ética del profesional y el cuerpo normativo que establece qué se debe y qué no se debe hacer en la práctica y ámbitos de incumbencia. El "entre" lo general y lo singular que atraviesa el encuentro con los sujetos de nuestra práctica. Singularidad que cuestiona las generalidades de la norma y pone al profesional ante situaciones de implicancias éticas y decisionales. 
Así, el profesional se ve enmarcado por la deontología y las legislaciones vigentes y la ética individual en su campo de acción. Omitir algunas de estas dos dimensiones excluye toda posibilidad del ejercicio profesional, pues el resguardo de la integridad de la salud del sujeto debe ser la prioridad que motive a cada profesional de la Psicología a formarse con sustento ético.

El profesional que pretende actuar responsablemente se verá preocupado por todo aquello que incida en su práctica y estará inclinado a intentar resolver disyuntivas, despejar dudas, indagar, profundizar y formarse en aspectos éticos de su quehacer.

De esta manera, para concluir tomamos las palabras del Profesor Juan Jorge Michel Fariña: "la salida ante ciertos dilemas éticos que se presentan en la práctica profesional al psicólogo no resulta por lo tanto deontológica sino decisional" (Salomone y Dominguez 2006: 7).

\section{Referencias Bibliográficas}

CASAS J. (2000). Los Retos de la Bioética en América Latina: Equidad, Salud y Derechos Humanos. Trabajo presentado en la Segunda reunión del Comité Asesor Internacional en Bioética. Organización Panamericana de la Salud-Organización Mundial de la Salud. Panamá.

FREUD, S. (1992). Conferencia la Transferencia. Conferencias de Introducción al Psicoanálisis. Obras Completas. Amorrortu. Buenos Aires.

FREUD, S. (1992). Inhibición Síntoma y Angustia. Obras Completas. Tomo XX. Amorrortu. Buenos Aires.

Hermosilla, A. (2002). Mala Praxis y Secreto Profesional. Responsabilidad y Ética profesional. Primeras Jornadas Nacionales de Psicología Jurídica. San Juan, Argentina.

LACAN, J. (2005). El Objeto y La Cosa. El Seminario 7: La Ética del Psicoanálisis. Paidós. Buenos Aires.

LACAN, J. (2005 b). Una Carta del Amor. El Seminario 20: Aún. Paidós. Buenos Aires.

MAINETTI, A. (1991). Bioética: De nominis Quaestio. Jurisprudencia Argentina.

1 Profesor Titular de la Cátedra de Psicología, Ética y Derechos Humanos, en la Facultad de Psicología. Universidad de Buenos Aires. Argentina. 
MAinetTI, J. A. (1998). Bioética Ficta. Quirón. La Plata. Argentina.

PERAltA, V. (2004). Reflexiones Respecto a la Certeza Ética y la Responsabilidad Profesional. En: "Deontología y Legislación Profesional”. Facultad de Psicología, Universidad Nacional de Córdoba. Argentina.

SALOMONE, G.; DOMínGUEZ, M. (2006). La transmisión de la ética. Clínica y deontología. Letra Viva. Buenos Aires

ZULUAGA, A. (2001). Ética y Conductas Suicidas. Revista Colombiana de Psiquiatría $\mathrm{N}^{\circ}$ 30. Consultado en agosto de 2009. Disponible en: http://redalyc.uaemex.mx/ pdf/806/80630404.pdf 